\title{
The Effectiveness of Mindfulness-Based Cognitive Group Therapy in Reducing Negative Automatic Thoughts and Dysfunctional Attitudes
} in Cancer Patients

\author{
Fatemeh Mehdipour, ${ }^{1}$ Amin Rafiepoor, ${ }^{2, *}$ and Kobra Haji Alizadeh ${ }^{1}$ \\ ${ }^{1}$ Department of Psychology, Bandar Abbas Branch, Islamic Azad University, Bandar Abbas, IR Iran \\ ${ }^{2}$ Department of Psychology, Faculty of Psychology and Educational Sciences, University of Sistan and Baluchestan, Zahedan, IR Iran \\ "Corresponding author: Amin Rafiepoor, University of Sistan and Baluchestan, Zahedan, IR Iran. Tel: +98-9128602243, Fax: +98-2188874333, E-mail: rafiepoor2000@yahoo.com
}

Received 2017 January 20; Revised 2017 March 28; Accepted 2017 June 25.

\begin{abstract}
Background: This study aimed to evaluate the effectiveness of mindfulness-based cognitive group therapy (MBCT) in reducing negative automatic thoughts and dysfunctional attitudes in cancer patients.

Methods: The study was an applied and quasi-experimental research conducted by pre- and post-testing. The sample consisted of 30 cancer patients selected by purposive sampling and randomly placed in the control and the experimental group (15 individuals per group). The members of both groups filled out the automatic thoughts questionnaire (ATQ) and the dysfunctional attitudes scale (DAS-26) at the pre- and the post-test stage. The collected data were analyzed by the SPSS software and multivariate analysis of covariance (MANCOVA) tests.

Results: The results indicated that MBCT significantly reduced negative automatic thoughts $(\mathrm{F}=126.15, \mathrm{P}<0.01)$ and dysfunctional attitudes $(\mathrm{F}=179.53, \mathrm{P}<0.01)$ in the experimental group at the post-test stage in comparison to the control group.

Conclusions: Based on the results of this study, it is essential that therapeutic centers and support forums related to patients with refractory disorders use MBCT in their programs for reducing negative automatic thoughts and dysfunctional attitudes.

Keywords: Cognitive Therapy, Mindfulness, Automatic Thoughts, Dysfunctional Attitude, Cancer
\end{abstract}

\section{Background}

Cancer is a disease characterized by abnormal cell growth and loss of cell differentiation. Cancer patients become afflicted with many physical, mental and social problems which may undermine the quality of their lives. Many research findings have indicated the relationship between mental health and quality of life in cancer patients [1]. The hurdles of cancer are the problems resulting from living with such patients. Cancer patients often suffer from multiple mental and psychological complications in addition to physical ones which lead to denial, neglect of treatment and health issues [2]. Among the aspects which undergo drastic change in cancer patients are quality of life, psychological well-being and mental health $[1,3]$. In this regard, psychologists put emphasis on thoughts and attitudes as predictors of mental health [4].

As negative mood sets in, old habits, automatic thoughts and ruminations begin in patients and as a result a major depressive episode may develop. Thoughts, beliefs and other cognitive processes are the main factors which determine a person's mood and emotions [5]. Dysfunctional attitude as a predisposing factor at the onset of depressive episodes comes into effect either directly or as a vulnerable factor under stressful environmental conditions [6]. Park et al. [6] state that dysfunctional communicative attitudes increase while quality of life decreases in cancer patients.

Patients afflicted with malignant diseases such as cancer are among the vulnerable population. Treatment of these patients is more often than not focused on stabilization of physical symptoms (pain, nausea and vomiting). With the development of the disease and its symptoms, patients tend to fear pain, suffering and negative automatic thoughts [7].

Kaplan and Sadock believe that when a patient needs help to overcome the problems and stresses resulting from non-adjustment to a disease, the environment, the family and the society, psychological intervention becomes imperative [8]. Considering what was said, it can be understood that cancer patients with all their problems and difficulties are in need of group therapies to improve their quality of life and reduce their negative automatic thoughts and dysfunctional attitudes.

Among the therapeutic and educational programs the MBCT can be prove a helpful method in this regard. During a MBCT educational course, depressed patients learn how to communicate with their negative thoughts and feelings 
and how to focus on changing their beliefs and thoughts. They also learn how to reorient their automatic thoughts, ruminations and negative thoughts and feelings, how to become aware of them and how to look at their thoughts and feelings from a broader perspective [9]. Mindfulness is a type of awareness which is formed when we bring our attention to our experiences about a specific subject; this attention is on purpose (it is brought to specific aspects of experience), occurs in the present moment (when the mind orients toward the future or the past, it gets reoriented toward the present) and is non-judgmental (it is accompanied by acceptance of what has happened) [10]. A MBCT program involves the following: (1) training awareness through mindfulness exercises, (2) an attitudinal framework developed by means of little effort, acceptance and inherent interest to experiences and (3) a process which links the understanding of the work procedure to vulnerable factors and training them [11]. This is facilitated during MBCT sessions through conversation, feedback, group exercises and training [10].

The positive effects of MBCT on psychological and mental problems of cancer patients have been proven in various studies [9-16]. Wood et al. [9] propose that MBCT is effective in restructuring dysfunctional thinking and negative cognitions in cancer patients. In this regard, the present study attempts to answer this question: Is MBCT effective in reducing negative automatic thoughts and dysfunctional attitudes in cancer patients?

\section{Methods}

This study was quasi-experimental conducted by preand post-testing the control and the experimental group. The study population consisted of all cancer patients who visited Shahid Mohammadi Hospital in Bandar Abbas Province in Iran for treatment. The sample consisted of 30 patients selected by purposive sampling, who were then randomly and equally divided into the control group and the experimental group (15 individuals per group). The Inclusion criteria for the sample are over 20 years old and have at least high school diploma. We don't have falling in sample. Considering that the recommended size for the sample population in experimental and quasiexperimental group studies is 15 individuals per group [17], the same number of subjects was chosen who were selected from among the study population according to the inclusion criteria. The selected subjects were then randomly placed in two 15-member groups.

The data collected from the study questionnaires in the pre-test and the post-test were initially described by descriptive statistics and then the multivariate analysis of covariance test (MANCOVA) was used in the inferential stage to analyze the study hypotheses and to control the pre-test effect using the SPSS software.

\subsection{Data Collection Instruments}

Automatic thoughts questionnaire (ATQ): this questionnaire contains 30 items designed for evaluation of depressive cognitions at the automatic thoughts level. This measure assesses four aspects of automatic thoughts: (1) personal conflict and desire for change, (2) negative selfconcept and expectations (3) low self-esteem and (4) hopelessness. Hollon and Kendall [18] designed this questionnaire for quick assessment of changes in self-talks of depressed patients. Easy implementation and scoring of the measure are among the reasons for wide-spread use of this questionnaire among experts in the field of cognitive therapy [5]. The psychometric characteristics of this questionnaire have been measured in Iran by Ghasemzadeh et al. [19]. According to the results of the study, the questionnaire's internal consistency was $\alpha=0.96$, its retest reliability was $r=0.84$ and its correlation coefficient was $\mathrm{BDI}=0.77$. The reliability of the study instruments were measured by Cronbach's alpha at 0.72 .

Dysfunctional attitudes scale (DAS-26): Wiseman and Beck's dysfunctional attitudes scale has been designed to assess dysfunctional attitudes based on Beck's cognitive theory. This questionnaire contains different ideas and opinions held by people. As for its psychometric characteristics, in a study by Ebrahimi et al. [20] the internal consistency of the 26 -item version was measured at 0.92 by the Cronbach's alpha method, which is more favorable than the 40-item version. It is also preferable over the shorter versions, such as Chioqueta and Stiles [21], wich et al. [22] and Kaviani et al. [23] in which Cronbach's alpha was measured at $0.85,0.86$ and 0.75 respectively. Considering the role of the dysfunctional attitudes scale in predicting cognitive vulnerability and mood and anxiety disorders, the concurrent criterion validity of DAS-26 was determined via its correlation with the total scores and the subscales of GHQ-28 and psychiatrist diagnosis. The correlation between DAS-26 and the prediction criteria is significant at the 0.99 confidence interval. These results are in conformity with Chioqueta and Stiles' [21] findings regarding the correlation between DAS and BDI-II $(r=0.47)$ and ATQ ( $r$ $=0.47$ ) regarding the correlation between DAS scores and structured interview $(r=0.41)$, the cognitive style questionnaire $(r=0.51)$ and BDI $(r=0.39)$ in addition to DAS's ability in predicting the probability of occurrence of mood and anxiety disorders $(\mathrm{OR}=12.020)$. Therefore, DAS-26 is a valid version for studying Iran's clinical population according to said findings. In factor analysis, four factors were identified for this 26-item version of DAS. The findings support the results of studies by Chioqueta and Stiles [21] and weich 
et al. [22] regarding identification of four factors in short versions. The validity of the scale was measured at 0.56 via health prediction by GHQ-28 scores. The correlation of the scale with the main questionnaire is 0.97 [24]. The reliability coefficient of the scale has been measured at 0.73 by retesting [25]. The reliability of the study instruments was measured at 80 by the Cronbach's alpha method. The procedure of a MBCT course has been given in Table 1 .

\begin{tabular}{|c|c|c|}
\hline No. & Session No. & Session Content \\
\hline $\mathbf{1}$ & First & $\begin{array}{l}\text { Overviewing chapters, Introducing MBCT, Reviewing } \\
\text { quality of life, Reducing automatic negative thoughts } \\
\text { and dysfunctional attitudes }\end{array}$ \\
\hline 2 & Second & $\begin{array}{l}\text { Awareness attention training with focus on full } \\
\text { awareness of feelings and thoughts via metacognition } \\
\text { therapy, Understanding the relationship between } \\
\text { thoughts and feelings }\end{array}$ \\
\hline 3 & Third & $\begin{array}{l}\text { Understanding and controlling the wandering mind, } \\
\text { Reviewing quality of life, Reducing automatic } \\
\text { negative thoughts and dysfunctional attitudes }\end{array}$ \\
\hline 4 & Fourth & Mindful breathing, Mindfulness meditation \\
\hline 5 & Fifth & $\begin{array}{l}\text { Continuing previous exercises, Achieving full } \\
\text { awareness of feelings and thoughts and accepting } \\
\text { them }\end{array}$ \\
\hline 6 & Sixth & $\begin{array}{l}\text { Creating a different relationship with experiences, } \\
\text { Understating how to create and use acceptance, } \\
\text { Changing mood and thoughts }\end{array}$ \\
\hline 7 & Seventh & $\begin{array}{l}\text { Reviewing the "thoughts are not facts" topic using } \\
\text { methods which involve viewing thoughts differently, } \\
\text { Self-caring and identifying relapse symptoms }\end{array}$ \\
\hline 8 & Eighth & $\begin{array}{l}\text { Reviewing previous sessions, Summarizing with the } \\
\text { help of participants to finish the course }\end{array}$ \\
\hline
\end{tabular}

${ }^{a}$ Participants received a homework handout at the end of each session.

\section{Results}

In this section, first the demographic variables and the research variables will be described. A total number of 30 subjects constituted the sample, who were all cancer patients in Bandar Abbas Province. Table 2 indicates negative automatic thoughts and dysfunctional attitudes mean distribution in the two groups at the pre- and post-test stage.

As it can be seen in Table 2, the negative automatic thoughts mean and the dysfunctional attitudes mean for the experimental group are 109.93 and 171.66 respectively in the pre-test and 61.86 and 105.6 respectively in the posttest. But, the means for the control group are 113.73 and 186.4 in the pre-test.

Prior to testing the research hypotheses and analysis of covariance, Levene's test was used to assess the assumption of equality of variances and the Kolmogorov-Smirnov
Table 2. Negative Automatic Thoughts and Dysfunctional Attitudes Mean Distribution in Both Groups ${ }^{\mathrm{a}}$

\begin{tabular}{lccc}
\hline Variable & Index & $\begin{array}{c}\text { Experimental } \\
\text { Group }\end{array}$ & Control Group \\
\hline $\begin{array}{l}\text { Negative } \\
\begin{array}{l}\text { Automatic } \\
\text { Thoughts }\end{array}\end{array}$ & Pre-test & $109.93 \pm 10.53$ & $113.73 \pm 5.33$ \\
$\begin{array}{l}\text { Dysfunctional } \\
\text { Attitudes }\end{array}$ & Pre-test & $171.66 \pm 15.31$ & $186.4 \pm 16.14$ \\
\hline
\end{tabular}

${ }^{\mathrm{a}}$ Values are expressed as mean \pm standard deviation.

test was used to assess the normal distribution of the research variables. The probability value of the KolmogorovSmirnov test is 0.209 for the negative automatic thoughts variable and 0.768 for the dysfunctional attitudes variable, which indicates a normal distribution of the variables in the sample. Therefore, parametric tests can be used to analyze the study results. The results of Levene's test have been presented in Table 3.

As it can be seen in Table 3, the null hypothesis for the equality of variances of the two groups in the research variables proves true. This means that the assumption of equal variances in the two groups proves true. Regarding this, the analysis of covariance test can be safely used. Now, the research hypotheses will be tested:

Prior to testing the research hypotheses and analysis of covariance, Levene's test was used to assess the assumption of equality of variances and the Kolmogorov-Smirnov test was used to assess the normal distribution of the research variables. The results proved the normal distribution of the variables in the sample. Also, the results of Levene's test confirm the null hypothesis for the equality of variances of the two groups in the research variables. This means that the assumption of equal variances in the two groups proves true.

The multivariate analysis of covariance test (MANCOVA) was used to compare the post-test means of negative automatic thoughts and dysfunctional attitudes in both groups after elimination of the pre-test effect. The results have been presented in Tables 4 and 5 .

As it can be seen in Table 4, the significance level of all tests indicates that there is a significant difference between the two groups in at least one of the dependent variables (negative automatic thoughts and dysfunctional attitudes). In order to better understand the difference, the results of the test of between-subjects effects have been presented in Table 5 .

As it can be seen in Table 5, there is a significant difference between the post-test means of negative automatic thoughts $(\mathrm{F}=126.15, \mathrm{P}<0.01, \eta=0.829)$ and dysfunctional 
Table 3. The Results of Levene's Test of the Equality of Variances in Both Groups

\begin{tabular}{lcccc}
\hline Variable & F & First Degrees of Freedom & Second Degrees of Freedom & Significance Level \\
\hline Automatic Negative Thoughts & 3.383 & 1 & 28 & 28 \\
Dysfunctional Attitudes & 0.21 & 1 & 0.077 \\
\hline
\end{tabular}

Table 4. The Results of Multivariate Analysis of Covariance for Comparing the Means of Negative Automatic Thoughts and Dysfunctional Attitudes in Both Groups

\begin{tabular}{lccccc}
\hline Test & Value & F & df Hypothesis & df Error & Significance Level \\
\hline Pillai's Trace & 0.876 & 88.36 & 2 & 25 & $0.0001^{\mathrm{a}}$ \\
Wilks's lambda & 0.124 & 88.36 & 2 & 25 & 0.876 \\
Hotelling's Trace & 7.069 & 88.36 & 2 & 25 & $0.0001^{\mathrm{a}}$ \\
\hline Roy's Largest Root & 7.069 & 88.36 & 2 & 25 & $0.0001^{\mathrm{a}}$ \\
\hline
\end{tabular}

${ }^{\mathrm{a}}$ Sig. $\mathrm{P}<0.01$.

Table 5. The Results of Analysis of Covariance for Comparing the Means of the Post-Test Scores of Negative Automatic Thoughts and Dysfunctional Attitudes in Both Groups

\begin{tabular}{|c|c|c|c|c|c|c|c|}
\hline Variable & Sources of Variation & Sum of Squares & Degrees of Freedom & Mean Square & $\mathbf{F}$ & Significance Level & Eta-Squared \\
\hline \multirow{3}{*}{$\begin{array}{l}\text { Automatic Negative } \\
\text { Thoughts }\end{array}$} & Pre-test & 1013.12 & 1 & 1013.12 & 6.56 & $0.017^{\mathrm{a}}$ & 0.023 \\
\hline & Group & 19470.26 & 1 & 19470.26 & 126.15 & $0.0001^{\mathrm{b}}$ & 0.829 \\
\hline & Error & 4012.87 & 26 & 154.34 & & & \\
\hline \multirow{3}{*}{$\begin{array}{l}\text { Dysfunctional } \\
\text { Attitudes }\end{array}$} & Pre-test & 303.31 & 1 & 303.31 & 1.39 & 0.248 & 0.051 \\
\hline & Group & 38961.01 & 1 & 38961.01 & 179.52 & $0.0001^{\mathrm{b}}$ & 0.873 \\
\hline & Error & 5642.56 & 26 & 217.02 & & & \\
\hline \multirow{2}{*}{ Total } & $\begin{array}{c}\text { Automatic Negative } \\
\text { Thoughts }\end{array}$ & 257993 & 30 & & & & \\
\hline & $\begin{array}{l}\text { Dysfunctional } \\
\text { Attitudes }\end{array}$ & 685878 & 30 & & & & \\
\hline
\end{tabular}

${ }^{\mathrm{a}} \mathrm{P}<0.05$

${ }^{\mathrm{b}}$ Sig. $\mathrm{P}<0.01$.

attitudes $(\mathrm{F}=179.53, \mathrm{P}<0.01, \eta=0.873)$ in the experimental group after elimination of the pre-test effect in the sense that the post-test means of negative automatic thoughts and dysfunctional attitudes in the experimental group are significantly lower than those of the control group. It can be proposed that MBCT has significantly reduced negative automatic thoughts and dysfunctional attitudes in the experimental group at the post-test stage in comparison to the control group. Therefore, the hypothesis that "MBCT is effective in reducing negative automatic thoughts and dysfunctional attitudes in cancer patients" proves true.

\section{Discussion}

The results of the study indicate that there is a significant difference in the post-test means of negative automatic thoughts and dysfunctional attitudes in the experi- mental group after elimination of the pre-test effect in the sense that the experimental group means are significantly lower than those of the control group. It can be proposed that MBCT has reduced negative automatic thoughts and dysfunctional attitudes in the members of the experimental group at the post-test stage in comparison to the members of the control group. This finding is in conformity with the study results achieved by Garcia et al. [26], Taimori et al. [12], Safa et al. [13], Omidi et al. [27], Yang et al. [14], Abbott et al. [15], Foley et al. [11] and Hofman et al. [16].

Recent findings have revealed that MBCT increases selfassertiveness, self-esteem, quality of life and positive feelings [28]. Mindfulness training also ameliorates psychological distress [29], depression and stress symptoms [30], improves mental, physical, emotional and spiritual wellbeing [31] and can consequently reduce negative automatic thoughts. Mindfulness improves quality of life, en- 
ables people to have more joy in life and reduces depression and anger [32]. It has also a significant role in reducing the short-term and long-term symptoms of depressed mood [33] and can reduce negative automatic thoughts and dysfunctional attitudes.

According to the results of this study, a significant difference is observable in the means of negative automatic thoughts of the experimental group in the post-test after elimination of the pre-test effect in the sense that these means are significantly lower than those of the control group. It can be proposed that MBCT has significantly reduced negative automatic thoughts in the experimental group at the post-test stage in comparison to the control group. This finding is in conformity with the study results achieved by Godfrin and Van Heeringen [33], Hofmann et al. [16], Schulman [34] and Shahrestani et al. [35].

A MBCT course emphasizes the necessity of replacement of negative automatic thoughts with rational beliefs in patients; therefore, the solutions introduced and presented to patients help them to identify negative thought patterns which induce the feeling of incompetence and replace them with rational functional thought patterns. All in-session exercises and the homework given to patients are very important since patients get the opportunity to practice confrontation with problematic and challenging situations in real life, and they can increase the effectiveness of the treatment. Furthermore, group sessions make it possible to receive feedback from other class members, create empathy, enable participants to observe how others confront negative automatic thoughts [36] and finally reduce negative automatic thoughts in patients.

However, the components of the MBCT course held for this study have resulted in reduced negative automatic thoughts in the subjects. These components were awareness training and resisting negative thoughts related to the disorder, developing communication skills in personal and social life through group discussion, increasing selfesteem via secure environment, homework and teamwork, developing and increasing motivation and commitment, assertiveness and responsibility skills training, reviewing negative automatic thoughts related to the disorder and other's viewpoints, discussing emotional awareness, predicting high-risk situations and preparing for helplessness against change and finally receiving feedback from other group members, all of which have positive effects on negative automatic thoughts.

The emanation sources of such thoughts are cognitive issues and they negatively affect life-satisfaction, undermine family foundations and intensify conflicts and disagreements [37]. At the same time, many studies have indicated the positive effects of MBCT on self-esteem, anxiety and stress $[12,37]$. Therefore, it can be said that MBCT can change negative automatic thoughts through affecting said variables. Since cognitions, emotions and awareness of their effects provide observable evidence of structural relationships between thoughts, feelings and behaviors [16], awareness of cognitions can affect feelings, behaviors and thoughts including negative automatic ones.

According to the results of this study, a significant difference is observable in the means of dysfunctional attitudes of the experimental group in the post-test after elimination of the pre-test effect in the sense that these means are significantly lower than those of the control group. It can be proposed that MBCT has significantly reduced dysfunctional attitudes in the experimental group at the posttest stage in comparison to the control group. This finding is in conformity with the study results achieved by Mohammadi et al. [27], Safa et al. [13], Jalali et al. [38] and Azargoun and Kajbaf [39].

According to Reivich and Shatte [40], MBCT and related educational courses can help with identification of negative thoughts and dysfunctional attitudes. Padesky and Mooney [41] believe that MBCT can eliminate factors such as dysfunctional attitudes. Therefore, dysfunctional attitudes are among the first issues to change via MBCT toward improvement of mental health in individuals especially patients. Waugh and Koster [42] state that treatments such as MBCT can have significant effects on health improvement.

Based on the results of this study, it can be said that MBCT is a type of psychotherapy which helps patients to non-judgmentally become aware and understand the thoughts and feelings which affect their behaviors [41]. Taylor et al. [43] state that MBCT enhances the cognitive skills which have inverse correlation with dysfunctional attitudes and as a result reduces such attitudes. According to Michalczuk et al. [44], all patients especially those afflicted with refractory diseases have many dysfunctional attitudes and destructive thought patterns. During a MBCT course, the patient learns how to identify destructive or annoying thought patterns which have negative effects on his behaviors and begins to understand their effects [43]. Dysfunctional attitudes are no exception to this and they can be corrected during this course. In most cases, MBCT is a gradual process that can help individuals to achieve change in mental and behavioral deviations step by step [45].

\section{Acknowledgments}

We would like to pay special thankfulness, warmth and appreciation to the persons who took part in this study and made our research successful and also to who assisted us at every point to cherish our goal. This paper is a part of the 
M.Sc. thesis "The effectiveness of mindfulness based cognitive therapy training on the quality of life, reducing negative automatic thoughts and dysfunctional attitude of cancer patients" (Ref. no. 61820701942017)" conducted by Fatemeh Mehdipour, supervised by Dr. Amin Rafiepoor and advised by Dr. Kobra Haji Alizadeh.

\section{Footnotes}

Authors' Contribution: All authors contributed extensively to the research presented in this paper.

Conflict of Interest: The authors declare that there's no conflict of interest.

Funding/Support: This study was supported by Islamic Azad University of Bandar Abbas.

\section{References}

1. Faller H, Schuler M, Richard M, Heckl U, Weis J, Kuffner R. Effects of psycho-oncologic interventions on emotional distress and quality of life in adult patients with cancer: systematic review and metaanalysis. J Clin Oncol. 2013;31(6):782-93. doi: 10.1200/JCO.2011.40.8922. [PubMed: 23319686].

2. Zainal NZ, Booth S, Huppert FA. The efficacy of mindfulness-based stress reduction on mental health of breast cancer patients: a metaanalysis. Psychooncology. 2013;22(7):1457-65. doi: 10.1002/pon.3171. [PubMed: 22961994].

3. Ryan RM, Deci EL. On happiness and human potentials: a review of research on hedonic and eudaimonic well-being. Annu Rev Psychol. 2001;52:141-66. doi: 10.1146/annurev.psych.52.1.141. [PubMed: 11148302].

4. Ghorbani K. The effect of intellectual-emotional-behavioral couple therapy on treatment of conflicts and irrational thoughts in couples visiting counseling centers in Isfahan City. Isfahan: University of Isfahan; 2005.

5. Teasdale JD, Segal Z, Williams JMG. How does cognitive therapy prevent depressive relapse and why should attentional control (mindfulness) training help? Behav Res Ther. 1995;33(1):25-39. doi:10.1016/00057967(94)e0011-7.

6. Park SG, Bennett ME, Couture SM, Blanchard JJ. Internalized stigma in schizophrenia: relations with dysfunctional attitudes, symptoms, and quality of life. Psychiatry Res. 2013;205(1-2):43-7. doi: 10.1016/j.psychres.2012.08.040. [PubMed: 22995038].

7. Ritvo P, Vora K, Irvine J, Mongrain M, Azargive S, Azam MA, et al. Reductions in negative automatic thoughts in students attending mindfulness tutorials predicts increased life satisfaction. Int J Educ Psychol. 2013;2(3):272-96.

8. Sarafino EP. Health Psychology. Tehran: Roshd Press; 2013.

9. Wood AW, Gonzalez J, Barden SM. Mindful caring: using mindfulnessbased cognitive therapy with caregivers of cancer survivors. J Psychosoc Oncol. 2015;33(1):66-84. doi: 10.1080/07347332.2014.977418. [PubMed: 25397963].

10. Crane R. Mindfulness-based cognitive therapy: distinctive features. Tehran: Be'that Press; 2011.

11. Foley E, Baillie A, Huxter M, Price M, Sinclair E. Mindfulness-based cognitive therapy for individuals whose lives have been affected by cancer: a randomized controlled trial.J Consult Clin Psychol. 2010;78(1):729. doi: 10.1037/a0017566. [PubMed: 20099952]

12. Teimouri S, Ramazani F, Mahjoob N. The effectiveness of mindfulnessbased group cognitive therapy in reducing depression and obsessive rumination among women under methadone treatment. JAddict Res. 2015;9(34):145-59.

13. Safa M, Ghassem Boroujerdi F, Karamlou S, Masjedi M. Effectiveness of mindfulness based on cognitive therapy, on distress tolerance and dysfunctional attitudes in patients with chronic obstructive pulmonary diseases. J Res Psychol Health. 2014;8(4):6-7.

14. Yang Y, Liu YH, Zhang HF, Liu JY. Effectiveness of mindfulness-based stress reduction and mindfulness-based cognitive therapies on people living with HIV: A systematic review and meta-analysis. Int J Nurs Sci. 2015;2(3):283-94. doi:10.1016/j.ijnss.2015.07.003.

15. Abbott RA, Whear R, Rodgers LR, Bethel A, Thompson Coon J, Kuyken W, et al. Effectiveness of mindfulness-based stress reduction and mindfulness based cognitive therapy in vascular disease: A systematic review and meta-analysis of randomised controlled trials. J Psychosomatic Res. 2014;76(5):341-51. doi: 10.1016/j.jpsychores.2014.02.012.

16. Hofmann SG, Sawyer AT, Witt AA, Oh D. The effect of mindfulnessbased therapy on anxiety and depression: A meta-analytic review. J Consult Clin Psychol. 2010;78(2):169-83. doi: 10.1037/a0018555. [PubMed: 20350028].

17. Yalom ID. The theory and practice of group psychotherapy. Basic Books (AZ); 1995.

18. Hollon SD, Kendall PC. Cognitive self-statements in depression: Development of an automatic thoughts questionnaire. Cogn Ther Res. 1980;4(4):383-95.

19. Ghassemzadeh H, Mojtabai R, Karamghadiri N, Ebrahimkhani N. Psychometric properties of a Persian-language version of the Beck Depression Inventory-Second edition: BDI-II-PERSIAN. Depress Anxiety. 2005;21(4):185-92. doi:10.1002/da.20070. [PubMed:16075452].

20. Ebrahimi A, Samouei R, Mousavii SG, Bornamanesh AR. Development and validation of 26-item dysfunctional attitude scale. Asia Paci Psychiatr. 2013;5(2):101-7. doi: 10.1111/appy.12020.

21. Chioqueta AP, Stiles TC. Personality traits and the development of depression, hopelessness, and suicide ideation. Pers Individ Differ. 2005;38(6):1283-91. doi: 10.1016/j.paid.2004.08.010.

22. Weich S, Churchill R, Lewis G. Dysfunctional attitudes and the common mental disorders in primary care. JAffect Disord. 2003;75(3):26978. [PubMed:12880939].

23. Kaviani H, Javaheri F, Bahiray H. Efficacy of mindfulness-based cog nitive therapy in reducing automatic thoughts, dysfunctional attitude, depression and anxiety: A sixty day follow-up. J Adv Cogn Sci. 2005;7(1):49-59.

24. Ebrahimi AA, Neshatdoust HT, Kalantari M, Moulavi H, Asad EGA. Contributions of dysfunctional attitude scale and general health subscales to prediction and odds ratio of depression. J Shahr-e kord Univ Med Sci. 2008;9(4):52-8.

25. Fata L. Identity statuses and their relation to identity styles and depression in Tehran juveniles. Tehran: Iran University of Medical Sciences; 2003.

26. Garcia-Soriano G, Roncero M, Perpina C. , Belloch A. Intrusive thoughts in obsessive-compulsive disorder and eating disorder patients: a differential analysis. Eur Eating Disord Rev. 2014;22(3):191-9.

27. Mohammadi A, Zargar F, Akkasheh G. Comparing the efficacy of combined Mindfulness Based Cognitive Therapy with Cognitive Behavioral Therapy and Traditional Cognitive Behavior Therapy in reducing dysfunctional attitudes of patients with Major Depressive Disorder. $J$ Birjand Univ Med Sci. 2014;20(4):383-92.

28. Coelho HF, Canter PH, Ernst E. Mindfulness-based cognitive therapy: evaluating current evidence and informing future research. J Consult Clin Psychol. 2007;75(6):1000-5. doi:10.1037/0022-006X.75.6.1000. [PubMed: 18085916].

29. Ostafin BD, Chawla N, Bowen S, Dillworth TM, Witkiewitz K, Marlatt GA. Intensive Mindfulness Training and the Reduction of Psychological Distress: A Preliminary Study. Cogn Behav Pract. 2006;13(3):191-7. doi: 10.1016/j.cbpra.2005.12.001. 
30. Evans S, Ferrando S, Findler M, Stowell C, Smart C, Haglin D. Mindfulness-based cognitive therapy for generalized anxiety disorder. J Anxiety Disord. 2008;22(4):716-21. doi: 10.1016/j.janxdis.2007.07.005. [PubMed:17765453].

31. Flugel Colle KF, Vincent A, Cha SS, Loehrer LL, Bauer BA, WahnerRoedler DL. Measurement of quality of life and participant experience with the mindfulness-based stress reduction program. Complement Ther Clin Pract. 2010;16(1):36-40. doi:10.1016/j.ctcp.2009.06.008.

32. Kieviet-Stijnen A, Visser A, Garssen B, Hudig W. Mindfulness-based stress reduction training for oncology patients: patients' appraisal and changes in well-being. Patient Educ Couns. 2008;72(3):436-42. doi: 10.1016/j.pec.2008.05.015. [PubMed: 18657376].

33. Godfrin KA, van Heeringen C. The effects of mindfulness-based cognitive therapy on recurrence of depressive episodes, mental health and quality of life: A randomized controlled study. Behav Res Ther. 2010;48(8):738-46. doi: 10.1016/j.brat.2010.04.006. [PubMed: 20462570].

34. Schulman P. Depression prevention in adults.J Cogn Ther. 2004;43:2371.

35. Shahrestani M, Qanbari BA, Hashem Nemati S, Rahbardar H. The Effectiveness of Mindfulness Based Cognitive Group Therapy (MBCT) on Improving Perceived Infertility-Related Stress and Irrational Parenthood Cognitions among Infertile Women Undergoing IVF Treatment. Iran J Obstetr Gynecol Infertil. 2012;15(19).

36. Tabatabaeichehr M, Ebrahimi Sani E, Mortazavi H. The effectiveness of group cognitive-behavioral psychotherapy on changing of irrational beliefs in male addicts. J North Khorasan Univ Med Sci. 2012;4(3):419-30.

37. Beyrami M, Hashemi T, Bakhshipour A, Mohammad Alilou M, Eghbali A. A comparison of the effects of emotional regulation and mindfulness-based cognitive therapy training methods on psycho- logical distress and cognitive strategies of emotional regulation in mothers of handicapped children.J Mod Psychol Res. 2014;9(33):43-59.

38. Jalali D, Aghaee A, Solati SK. Comparing the effectivness of Natived Mindfulness Based Cognitive Therapy (nMBCT) according to IranianIslamic culture and Cognitive-Behavioral Therapy (CBT) on blood presure. J Shahrekord Uuniv Med Sci. 2017;18.

39. Azargoun H, Kajbaf MB. Effectiveness of mindfulness in reducing dysfunctional attitudes and automatic thoughts in depressed students of Isfahan University. Iran J Psychol. 2010;14(53):79-94.

40. Reivich K, Shatte A. The resilience factor: 7 keys to finding your inner strength and overcoming life's hurdles. Harmony; 2003.

41. Padesky CA, Mooney KA. Strengths-based cognitive-behavioural therapy: a four-step model to build resilience. Clin Psychol Psychother. 2012;19(4):283-90. doi: 10.1002/cpp.1795. [PubMed: 22653834].

42. Waugh CE, Koster EH. A resilience framework for promoting stable remission from depression. Clin Psychol Rev. 2015;41:49-60. doi: 10.1016/j.cpr.2014.05.004. [PubMed: 24930712].

43. Taylor JL, Lindsay WR, Willner P. CBT for people with intellectual disabilities: emerging evidence, cognitive ability and IQ effects. J Behav Cogn Psychother. 2008;36(6):723-33.

44. Michalczuk R, Bowden-Jones H, Verdejo-Garcia A, Clark L. Impulsivity and cognitive distortions in pathological gamblers attending the UK National Problem Gambling Clinic: a preliminary report. Psychol Med. 2011;41(12):2625-35. doi: 10.1017/S003329171100095X. [PubMed: 21733207].

45. Khakpour M, Mehrafarid M. The effect of group cognitive-behavioral intervention in reducing dysfunctional attitudes, hopelessness and suicidal thoughts in young prisoners. JCrime Prev Stud. 2012;7(25):13959. 